\begin{tabular}{|l|l|}
\hline & \\
\hline
\end{tabular}

OUTROS TEMAS

\title{
Um olhar sobre o discurso da formação continuada de professores
}

\author{
A look at the speech of the continued formation of teachers \\ Una mirada sobre el discurso de la formación continuada de profesores
}

\section{Eduardo Antonio De \\ Pontes Costa ${ }^{1}$}

orcid.org/0000-0002-8072-1777

eduapcosta@gmail.com

\section{Décio Pereira de Brito ${ }^{1}$ \\ orcid.org/0000-0002-3402-6861 \\ debritopereira@gmail.com}

Recebido em: 27 mar. 2018.

Aprovado em: 14 dez. 2019

Publicado em: 25 mai. 2020.
Resumo: Esta investigação procura discutir os saberes da formação continuada de professores do Centro de Capacitação de Professores (Cecapro), da Secretaria de Educação e Cultura (Sedec), do municipio de João Pessoa. Com base nos conceitos de discurso e de enunciado formulados por Michel Foucault (2008) e de diário de pesquisa de campo presente em René Lourau (1993), é tomado como analisador o Processo Licitatório n. ${ }^{\circ}$ 007663/2009. As análises focam a emergência da profissionalização docente, as áreas de seguimentos de atuação do professor no ensino fundamental e o perfil do professor formador. Conclui-se que os professores em formação, inscritos na prescrição do saber-fazer pedagógico, passam a ocupar, nos ditos do Processo Licitatório, lugares especificos, e a disputar determinados discursos, pretensamente aceitos como neutros e verdadeiros. Palavras-chave: formação continuada, discurso, enunciado, sujeito.

Abstract: This research aims at discussing the knowledge of teacher education carried out by the Center for Teacher Training (CECAPRO), of the Department of Education and Culture (SEDEC), in the city of João Pessoa. Based on the concepts of discourse and utterance formulated by Michel Foucault (2008) and of field diary research in René Lourau (1993), is taken as analyzer the Bidding Process $n^{\circ} 007663$. of 2009. The analyzes focus on the emergence of teacher professionalization, the areas of follow-up of the teacher's performance in elementary school and the profile of the teacher trainer. It is concluded that teachers in training, enrolled in the prescription of pedagogical know-how, now occupy, in the sayings of the Bidding Process, specific places and to dispute certain speeches, allegedly accepted as neutral and true.

Keywords: continued formation, discourse, utterance, subject.

Resumen: Esta investigación busca discutir los saberes de la formación continuada de profesores realizada por el Centro de Capacitación de Profesores (CECAPRO), de la Secretaría de Educación y Cultura (SEDEC), de la Ciudad de João Pessoa. Con base en los conceptos de discurso y enunciado formulados por Michel Foucault (2008) y de diario de investigación de campo en René Lourau (1993), se toma como analizador el Proceso Licitatorio nº $007663 / 2009$. Los análisis enfocan la emergencia de la profesionalización docente, las áreas de seguimiento de actuación del profesor en la enseñanza fundamental y el perfil del profesor formador. Se concluye que los profesores en formación, inscritos en la prescripción del saber hacer pedagógico, pasan a ocupar, en los dichos del Proceso Licitatorio, lugares específicos ya disputar determinados discursos, supuestamente aceptados como neutros y verdaderos.

Palabras clave: formación continuada, discurso, enunciado, sujeto. 
A discussão que vem pautando os efeitos das políticas educacionais direcionadas à valorização da formação de professores assevera a relevância, em especial, da formação continuada como discurso e prática ancorados nas plataformas de implementação, em que União, Estados e Municípios, com base nos dispositivos legais, dialogam e integram ações no campo do direito à educação, no sentido de garantir esse mesmo direito no continuum e complexo processo de constituir-se no cargo de professor.

Pesquisas indicam que o sintagma "formação continuada", pela dimensão de contexto social, é recente no âmbito educacional. Para Cruz Júnior, Fontes e Loureiro (2014, p. 199), ainda que "(...) a formação continuada dos profissionais da educação tenha assumido uma posição de destaque nas discussões relativas a esse campo de estudo, o seu surgimento é muito recente no campo educacional. (...)".

Por outro lado, Gatti (2008, p. 57) afirma que, no plano conceitual, as pesquisas e as reflexões sobre a noção de educação continuada nos estudos educacionais não dão conta de "precisar" o conceito, muito embora a autora entenda que "(...) talvez isso não seja mesmo importante, aberto que fica ao curso de história (...)". Ela assegura, inclusive, que:

(...) nesses estudos, ora se restringe o significado da expressão aos limites de cursos estruturados e formalizados oferecidos após a graduação, ou após ingresso no exercício do magistério, ora ele é tomado de modo amplo e genérico, como compreendendo qualquer tipo de atividade que venha a contribuir para o desempenho profissional - horas de trabalho coletivo na escola, reuniões pedagógicas, trocas cotidianas com os pares, participação na gestão escolar, congressos, seminários, cursos de diversas naturezas e formatos, oferecidos pelas Secretarias de Educação ou outras instituições para pessoal em exercicio nos sistemas de ensino, relações profissionais virtuais, processos diversos a distância (vídeo ou teleconferências, cursos via internet etc.), grupos de sensibilização profissional, enfim, tudo que possa oferecer ocasião de informação, reflexão, discussão e trocas que favoreçam o aprimoramento profissional, em qualquer de seus ângulos, em qualquer situação. Uma vastidão de possibilidades dentro do rótulo de educação continuada (Gatti, 2008, p. 57)
Levando-se em consideração a indicação segura da complexidade e dos desafios que marcam o campo da formação inicial e continuada de professores, como Freitas (2007), Gatti (2008) e Brzezinski (2014) apontam, identificamos que o Ministério da Educação (MEC) dispõe, nos dias atuais, de oito programas estratégicos de ação dirigidos, executados pelos sistema de ensino e direcionados à formação continuada: (a) Formação no Pacto Nacional pela Alfabetização na Idade Certa (PNAIC); (b) Prolnfantil; (c) Plano Nacional de Formação de Professores da Educação Básica (PARFOR); (d) Proinfo Integrado; (e) e-Proinfo; (f) Pró-letramento; (g) Gestar Il; e (h) Rede Nacional de Formação Continuada de Professores. Há, sem dúvida, uma clara tentativa de assegurar, minimamente, o direito à formação continuada conforme constam na Lei de Diretrizes e Bases da Educação Nacional (LDB), Lei n. ${ }^{\circ}$ 9394/1996, em específico, no seu Art. 40 e no Decreto . $^{\circ}$ 6.755, de 29 de janeiro de 2009, revogado pelo Decreto $n^{\circ}$ 8.752 de 2016 que dispõe sobre a Política Nacional de Formação dos Profissionais da Educação Básica.

Pode-se afirmar que a pertinência dessas estratégias tem, e aproximando-se aqui do trabalho analítico de Gatti (2008), uma:

(...) base histórica em condições emergentes na sociedade contemporânea, nos desafios colocados aos currículos e ao ensino, nos desafios postos aos sistemas pelo acolhimento cada vez maior de crianças e jovens, nas dificuldades do dia a dia nos sistemas de ensino, anunciadas e enfrentadas por gestores e professores e constatadas e analisadas por pesquisas. Criaram-se o discurso da atualização e o discurso da necessidade de renovação. (p. 58).

Vale ressaltar que, nas condições emergentes da sociedade capitalista, baseada na noção do sujeito-flexível e do tempo de curto prazo, os enunciados de competência, atitudes e habilidades não apenas se materializam nas propostas curriculares dos cursos de formação inicial e continuada de professores mas inventam um novo tipo de homem, um novo tipo de trabalhador, ao tentar responder a uma certa urgência de sujeito.

Nesse sentido, a hipótese de Florestan Fernandes (1986) é atual e desafiadora para 
pensar a "limitação do horizonte cultural do professor" na tradição da cultura brasileira. Segundo Fernandes (1986,), há uma cultura cívica circunscrita e fechada. A cultura civica seria "(...) aquilo que a sociedade toda está construindo, nas piores condições possiveis que poderiamos imaginar e, portanto, é decisivo que o educador volte a pensar em como fundir os seus papéis dentro da classe de aula, com papéis dentro da sociedade" (p. 23). Sociedade que, marcada pelas desigualdades sociais, sempre buscou, como um ciclo vicioso, negar o direito à educação. Conforme Freitas (2007, p. 1204) afirma, compreender "(...) essas amarras sociais é importante para que não criemos ilusões de soluções fáceis para os problemas da educação e da formação. (...)".

$\mathrm{E}$ aqui vale a pena questionar: como uma ação local tem se dedicado à formação continuada do professor no sentido de produzir transformações sociais?

Com base nessas considerações, a trajetória do presente artigo busca problematizar os saberes da formação continuada, realizada nos arquivos do Centro de Capacitação de Professores (Cecapro), da Secretaria de Educação e Cultura (Sedec), do município de João Pessoa, ao tomar como questões especíicas os saberes que produzem e atualizam modos de ser docente. Quando tomados tais saberes como verdadeiros e, provavelmente, inquestionáveis, haveria espaços, na qualificação em serviço, para pensar a prática pedagógica de modo criativo e inventivo? Como determinados enunciados se organizam no sentido de estruturar e constituir uma prática discursiva do professor?

\section{Discurso e enunciado como prática discursiva}

A compreensão de discurso e de enunciado elaborada pela analítica de Michel Foucault remete à noção de linguagem, como constitutiva do nosso pensamento, e do significado e do sentido que atribuimos às nossas experiências (Veiga, 2007).

(...) Para Foucault, o sujeito de um discurso não é a origem individual e autônoma de um ato que traz à luz os enunciados desse discurso; ele não é o dono de uma intenção comunicativa, como se fosse capaz de se posicionar de fora desse discurso para sobre ele falar. (...). (Veiga, 2007, p. 91).

O percurso lógico de Michel Foucault liga-se ao pensamento de Friedrich Nietzsche quando esse vai mostrar o caráter arbitrário e não natural da linguagem, bem como o caráter também não natural da moral (Veiga, 2007)

No primeiro caso, o que está enunciado
é uma convenção de linguagem - dessa
linguagem que deve ser utilizada pelo
sujeito enunciante e no interior da qual
ele se define: o sujeito enunciante e o
que é enunciado estão no mesmo nivel
(enquanto, para uma análise formal, um
enunciado como esse implica o desni-
velamento próprio da metalinguagem).
No segundo caso, ao contrário, o sujeito
enunciante faz com que exista, fora
de si, um objeto que pertence a um
dominio já definido, cujas leis de pos-
sibilidade já foram articuladas e cujos
caracteres são anteriores à enunciação
que o coloca. (...). (Foucault, 2008, p. 107).

A noção de discurso, lugar de irrupção dos conceitos, não remete o discurso à distante presença da origem. Ao contrário, para Lecourt (2008), é preciso compreender por que Foucault define o discurso de modo tão ímpar, pois é necessário situá-lo no jogo da sua emergência.

Essas formas prévias de continuidade todas essas sinteses que não problematizamos e que deixamos valer de pleno direito, é preciso, pois, mantê-las em suspenso. Não se trata, é claro, de recusá-las definitivamente, mas sacudir a quietude com a qual as aceitamos: mostrar que elas não se justificam por si mesmas, que são sempre o efeito de uma construção cujas regras devem ser conhecidas e cujas justificativas devem ser controladas; (...). (Lecourt, 2008, p. 28).

Para que um discurso seja legítimo e para que ele possa existir, para que o sujeito possa dizer alguma coisa em um determinado momento, são necessárias condições materiais de existência que irão atribuir um estatuto de verdade ao próprio discurso. No dizer de Lecourt (2008, p. 51), "(...) se o que foi dito do 'regime material do enunciado' é exato, o discurso não é definivel independentemente das relações que o constituem; é assim que se falará de 'relações discursivas', ou 'regularidades discursivas', de preferência a 'discurso'". 
Ainda de acordo com Lecourt (2008), o discurso seria, em última análise, uma prática que não deve ser compreendida como a atividade de um sujeito, mas a existência objetiva e material de determinadas regras a partir das quais o indivíduo tem que enunciar quando participa de uma certa ordem do discurso.

É importante destacar, portanto, que os discursos "(...) não estão ancorados ultimamente em nenhum lugar, mas se distribuem difusamente pelo tecido social, de modo a marcar o pensamento de cada época, em cada lugar, e, a partir daí, construir subjetividades" (Veiga, 2007, p. 100).

As relações discursivas estão, portanto,

(...) de alguma maneira, no limite do discurso: oferecem-lhe objetos de que ele pode falar, ou antes (pois essa imagem da oferta supõe que os objetos sejam formados de um lado e o discurso, do outro), determinam o feixe de relações que o discurso deve efetuar para poder falar de tais ou tais objetos, para poder abordá-los, nomeá-los, analisá-los, classificá-los, explicá-los etc. (...). (Foucault, 2008, p. 51).

Situar o discurso enquanto prática é perguntar pelos processos que fabricam determinados objetos, em que relações discursivas caracterizam "(...) não a língua que o discurso utiliza, não as circunstâncias em que ele se desenvolve, mas o próprio discurso enquanto prática" (Foucault, 2008, p. 52). Segundo Veyne (1982), diferentes práticas produzem diferentes objetos, relacionando-os, sobretudo,

(...) ao conjunto de regras que permitem formá-los como objetos de um discurso e que constituem, assim, nas condições de aparecimento histórico; fazer uma história dos objetos discursivos que não os enterre na profundidade comum de um solo imaginário, mas que desenvolva o nexo das regularidades que regem sua dispersão. (Foucault, 2008, pp. 53-54).

A análise da categoria enunciado proposta por Foucault (2008, p. 90) permite pensar o enunciado não como um ato de linguagem ou um ato de proposição. E, se o enunciado é a unidade elementar do discurso, em que ele consiste?

O enunciado não é, pois, uma estrutura (isto é, um conjunto de relações entre elementos variáveis, autorizando assim um número talvez infinito de modelos concretos); é uma função de existência que pertence, exclusivamente, aos signos, e a partir da qual se pode decidir, em seguida, pela análise ou pela intuição, se eles "fazem sentido" ou não, segundo que regra se sucedem ou se justapõem, de que são signos, e que espécie de ato se encontra realizado por sua formulação (oral ou escrita). (Foucault, 2008, p. 98).

O enunciado, como instância produtora, deve ser descrito como acontecimento. Nos processos de subjetivação da formação continuada - objeto da presente investigação -, quais regras produzem e atualizam modos de dizer e de pensar? Quais enunciados devem ser mantidos enquanto existência material? Como o enunciado "(...) é um tipo muito especial de um ato discursivo" (Veiga, 2007, p. 94), do ponto de vista metodológico, ele deve ser analisado em um complexo feixe de relações que permite identificá-lo e descrevê-lo, assim como o discurso, pela sua regularidade (Lecourt \& Rouanet, 2008, 2008).

Para a análise da função enunciativa, Foucault (2008) vai dizer que não há enunciado que não suponha outros, certamente, pela materialidade de certas condições históricas de emergência. Nessa direção, o autor irá caracterizar quatro condições para que uma sequência linguística possa ser considerada e analisada como um enunciado: (a) um referencial - forma o lugar, a condição, o campo de emergência etc.; (b) uma posição do sujeito - posições que ele ocupa na ordem dos discursos; (c) um domínio associado - coexistência de outros enunciados; (d) e uma existência material - os ditos, os escritos etc., em um determinado momento histórico.

Observe-se que Rouanet (2008) afirma que as regras que definem a posição do sujeito surgem de contextos institucionais que autorizam a produção de um certo sujeito produtivo e consciente. Tais regras para a constituição de temas emanam da função das práticas não discursivas, "(...) que se apropriam de determinados discursos: por exemplo, a prática do capitalismo nascente articulando-se no discurso econômico e a prática pedagógica articulando-se na gramática geral" (p. 119). 


\section{As ferramentas da pesquisa}

Com base em uma investigação documental, na perspectiva de Michel Foucault (2008), é desenvolvida uma análise do discurso da formação continuada, inscrita no Processo Licitatório n. ${ }^{\circ}$ 007763/2009, Anexo I, Termo de Referência, Concorrência n. ${ }^{\circ}$ 02/2009, da Seleção de Projetos para execução da "Formação Continuada dos Trabalhadores da Educação", da Rede Municipal de Ensino de João Pessoa.

A proposta da análise de discurso segue, da mesma forma, o referencial teórico de Michel Foucault, quando se considera que a análise é "(...) a análise das relações entre aqueles 'outros fenômenos', a erupção do discurso e o dictum" (Veiga, 2007, p. 100). Busca-se tratar, dessa forma, o discurso e o enunciado problematizando-se o saber - objeto próprio da arqueologia (Lecourt, 2008), nos processos de subjetivação.

Apoiados em uma pesquisa qualitativa (Goldenberg, 1997), a coleta de dados foi realizada no Centro de Capacitação de Professores (Cecapro), da Secretaria de Educação e Cultura (Sedec), órgão executor e articulador do sistema de ensino municipal.

O instrumento de coleta de dados foi apoiado na captura de dados do diário de pesquisa de campo elaborado pelo bolsista do Programa Institucional de Bolsas de Iniciação Cientíica (PIBIC/UFPB/CNPq). Para Lourau (1993, p. 77), o diário de pesquisa "(...) nos permite o conhecimento da vivência cotidiana de campo (não o 'como fazer' das normas, mas o 'como foi feito' da prática)", a partir do registro do autor-pesquisador, em que as percepções, as observações, os sentimentos de medo, de alegria etc., eram tomados em notas no diário.

É importante destacar que, para analisar os saberes da formação continuada nos ditos do Processo Licitatório n. ${ }^{\circ}$ 00733/2009, e entendidos como objetos de uma prática, serão inseridos, a título de ilustração, alguns excertos retirados do próprio documento. Sob esse ponto de vista e para uma análise do discurso, evocamos as quatros condições de materialidade de um enunciado: um referencial, uma posição do sujeito, um domínio associado e uma existência material. Desse modo, as análises estão estruturadas a partir de três eixos: (a) a emergência da profissionalização docente; (b) as áreas de seguimento da prática docente; (c) e o perfil do professor formador.

\section{A emergência da profissionalização docente}

O discurso e a materialidade das reformas do Estado brasileiro no início da década de 1990 apontam para profundas e rápidas transformações no cenário econômico e social, com a expressiva adoção da política neoliberal, traduzida em privatizações, perdas de direitos no campo do social e do trabalho, redução de gastos públicos em setores importantes da sociedade como saúde, educação, habitação etc. Neste cenário de profundas transformações, um modo de gestão sobre a vida busca definir e alinhar um novo perfil de professor: o sujeito da competência e da habilidade.

A Lei de Diretrizes e Bases da Educação Nacional (LDB), Lei n. ${ }^{\circ}$ 9394/1996 e o Decreto n. ${ }^{\circ} 6.755$, de 29 de janeiro de 2009, revogado pelo Decreto n. 8.752 de 2016 que dispõe sobre a Política Nacional de Formação dos Profissionais da Educação Básica, representam, em decorrência da participação do Estado com setores da Educação e dos movimentos sociais na luta por uma escola pública, de qualidade e para todos, legislações importantes oriundas do contexto das reformas de Estado. A profissionalização docente, como uma política de formação, é instituida a partir de regras e principios especificos e operadores para os critérios de como os entes parceiros - União, Estados e Municipios - deverão focar seus esforços no sentido de buscar equacionar os recorrentes problemas para o magistério da educação básica. Neste sentido, o professor passa a ser objeto estratégico para ser não apenas "competente e habilidoso" na sua área especifica de formação como também promover uma educação de qualidade para crianças e jovens. Desse modo, a formação do professor:

(...) caracteriza-se pela criação dos Institutos Superiores de Educação e pela diversificação e flexibilização da oferta dos cursos de formação - normais superiores, pedagogia, licencia- 
turas, cursos especiais e cursos à (sic) distância -, de modo a atender a (sic) crescente demanda pela formação superior. (Freitas, 2007, p. 1208).

No Decreto n. 8.752 de 2016, em seu Artigo $1^{\circ}$, que trata da finalidade de fixar seus principios e objetivos, e de organizar programas e ações, o §3. ${ }^{\circ}$ diz que o MEC deverá garantir, ao coordenar a Política Nacional de Formação dos Profissionais da Educação Básica, sua coerência com as Diretrizes Nacionais do Conselho Nacional de Educação (CNE), a Base Nacional Comum Curricular (BNCC), os Processos de Avaliação da Educação Básica e Superior, os Programas e as Ações Supletivas do referido Ministério, e com as iniciativas e programas de formação implementados pelos Estados, Distrito Federal e Municipios.

Na contramão da perspectiva apresentada, Brzezinski (2014) afirma, enfaticamente, que as ações do MEC apresentam um "descompasso" em relação às legislações específicas.

Na definição e desenvolvimento das politicas de formação de profissionais da educação, constata-se, contudo, que o governo nas duas últimas décadas opta por práticas de políticas pontuais e emergenciais, por meio de planos e programas dispersos, marcados pela inorganicidade e desarticulação do próprio Ministério da Educação (MEC). No âmbito dessas politicas, ignora-se a importância de um controle social sistemático, o que implica malversação de recursos públicos. Na verdade, não existe uma política pública global de formação e valorização dos profissionais da educação, de modo que se articule a qualidade social dos processos formativos com condições dignas de trabalho, carreira e planos de cargos e salários com base no piso salarial nacional. (Brzezinski, 2014, p. 1243).

Ao tentarmos assinalar as condições de emergência da profissionalização do magistério para a educação básica - com foco na formação continuada de professores que atuam na modalidade do ensino fundamental -, buscamos indicar as possiveis interfaces da proposta licitatória com o que preconiza a legislação especifica sobre o perfil do trabalhador na Educação.

Quando analisamos no Processo Licitatório, em especíico, no Anexo I, Termo de Referência - Especificações do Objeto -, identificamos os seguintes enunciados:

\section{DAS DISPOSIÇÕES GERAIS \\ 1.1 JUSTIFICATIVA}

A Secretaria de Educação Municipal de João Pessoa, órgão executor e articulador do sistema de ensino da Rede Municipal, formulou diretrizes básicas para o seu processo de formação dos educadores objetivando a qualidade e efetividade do trabalho do educador, em razão da melhoria do ensino-aprendizagem dos alunos matriculados nas escolas do municipio. (Processo Licitatório, n. ${ }^{\circ}$ 007663/2009).

É importante destacar aqui uma análise que se situa, provavelmente, em uma dimensão "performática" de determinadas expressões que passam a demarcar uma certa regularidade em relação ao sujeito da qualificação profissional. "Qualidade" e "Melhoria" são expressões que indicam para duas leituras: a primeira remete à transcrição do texto legal nos ditos do Decreto n. 8.752 de 2016, especificamente, nos Princípios IV e VIII; e a segunda, estabelece um modo de prescrever o saber-fazer docente. Compreendemos que "qualidade" e "melhoria" do trabalho docente, muito embora sejam expressões significativas do ponto de vista da unidade do trabalho na escola, articula-se com demandas legitimas de quem, efetivamente, encontra-se no chão da escola? Em que bases podemos falar de "qualidade" e "melhoria" em decorrência, apenas, do ensino-aprendizagem dos alunos? Estaríamos falando da "flexibilização" da formação docente, no dizer de Freitas (2007)?

A respeito da concepção de formação, há uma racionalidade na produção e atualização do professor que atua no Ensino Fundamental. Vejamos o que indicam as estratégias enunciativas sobre a formação continuada:

A formação enquanto processo permanente de produção de saberes oferecerá aos educadores o apoio teórico-metodológico com vistas ao redimensionamento das ações práticas desses educadores, em razão da melhoria da qualidade do ensino-aprendizagem. 
Nessa perspectiva, a formação deve ser redimensionada a partir de uma profunda e permanente reflexão crítica sobre as ações de capacitação realizadas pela Secretaria de Educação de modo que haja o resgate da escola como o espaço mais significativo dos educadores realizarem os seus processos de formação.

Em sintese, a formação assim concebida relaciona o prático e o teórico de modo que os educadores superem a visão de uma formação fragmentada e desvinculada do seu cotidiano para uma formação consequente em que o teórico se articula com a prática e com os novos conhecimentos cientíicos e tecnológicos em razão de uma educação transformadora no espaço escolar. (Processo Licitatório, n. ${ }^{\circ}$ 007663/2009).

Quais enunciados sustentam o professor em formação - objeto de uma discursividade? E quais os efeitos são produzidos em meio às práticas históricas e contingenciais? Quando olhamos para a proposição da formação docente buscando compreender nessas estratégias enunciativas as orientações da formação continuada no tocante às relações de saber-poder, e entendidas como constituidoras de subjetividades, instaura-se aqui uma certa "tecnologia do eu", um certo modo de operar o magistério. Tais estratégias sugerem pensar o "sujeito da formação" da Sedec transversalizado por elementos significantes, mantenedores e reguladores de uma anátomopolítica do corpo. Ao incorporar "novos" elementos para a formação, tal proposição estabelece no jogo discursivo a fabricação do "olhar para si", enquanto produção, cujos fios de "atualização" do sujeito vão enunciar os professores aptos e competentes para a "melhoria da qualidade do ensino", ao propor a irrupção do sujeito "polivalente, crítico", e que saiba relacionar teoria e prática.

E, ainda, indagamos: como se dão as decisões pedagógicas do professor? É possivel "resgatar" a qualidade da formação docente quando a história da Educação em nosso País indica e direciona para problemas estruturais na profissionalização dos professores? Como superar a "fragmentação" da formação continuada frente ao paradigma do "sujeito-flexivel", "fragmentado", "endividado" etc.?

Geglio (2015, pp. 244-245) nos chama atenção, ainda dentro dessas questões, para algumas "incompatibilidades" entre as propostas da formação continuada da Sedec e o instante da qualificação em serviço. Ele diz, de forma contundente, que:

Cerca de 50\% da carga horária dos cursos era destinada ao acompanhamento do trabalho do professor. Essa etapa segundo nossa percepção, se resumiu a tirar dúvidas dos professores sobre o que aprenderam, desde que eles se dirigissem a uma escola polo, onde estaria uma pessoa para esse fim. O restante das horas declaradas para o curso foi destinado aos encontros presenciais. Consideramos que tais momentos foram muito espaçados entre si. o que desfavorece a continuidade das discussões, ocasionando possibilidades de desestimulos nos professores. Esse tipo de curso pode ser considerado tradicional, pois nele são feitas abordagens de assuntos genéricos da educação ou de conteúdos das disciplinas, de forma descontextualizada dos problemas cotidianos dos professores. Além disso, não percebemos registros de que o professor foi ouvido sobre a sua necessidade de formação. Nem antes, nem depois do curso, os professores foram consultados a respeito da formação que receberam.

De acordo com o Processo Licitatório n. ${ }^{\circ}$ 007663/2009, a formação como processo de produção de saberes "(...) oferecerá aos educadores o apoio teórico-metodológico com vistas ao redimensionamento das ações práticas desses educadores, em razão da melhoria da qualidade do ensino-aprendizagem". E cabe, ainda, indagar: que apoio didático-pedagógico o professor teve durante a formação continuada? Como se deu?

\section{Áreas de seguimento da prática docente}

Na proposta de aprimoramento em serviço, observamos o estabelecimento de alguns critérios para a inscrição do professor, de acordo com as orientações do Processo Licitatório: (a) as inscrições são individuais e por segmento; (b) cada estabelecimento de ensino poderá viabilizar a inscrição de seus educadores; (c) cabe aos diretores verificar se todos os professores efetivaram sua inscrição na Formação de acordo com o segmento; e (d) a dispensa da formação continuada para o profissional cursando pósgraduação está vinculada à abertura de processo 
na Sedec constando de declaração atualizada (reconhecida em cartório), e emitida pela coordenação do curso etc.

Tomando a escola como espaço importante na produção de saberes, o referido Processo apresenta como eixo comum os seguintes enunciados: a) a transversalidade - ética, meio ambiente, saúde, sexualidade, violência, uso e abuso de drogas lícitas e ilícitas; b) educação inclusiva; c) educação para o trânsito; e d) etnia, gênero e cultura.

É evidente que tais enunciados acompanham o que preconizam as orientações dos Parâmetros Curriculares Nacionais (PNCs), de 1998. Do ponto de vista da relação entre teoria e prática do saberfazer docente, em uma perspectiva dialogada com outros campos de saber, a transversalidade desses temas se articula com a questão da interdisciplinaridade quando os professores procuram estabelecer relações, conexões com o contexto do aluno, com o seu próprio contexto, enfim, com o cotidiano escolar, sempre diverso, desafiador e singular. Nessa relação pedagógica de ressignificação, algumas questões são levantadas: como se deu a escolha pela Sedec desses temas transversais? Uma vez a escolha definida, quais critérios preponderaram? Quais sujeitos participaram da escolha e, consequentemente, da definição dos critérios aplicados?

Bonfim et al. (2013, p. 30) levantam questões importantes que se encaminham nessa direção. Vejamos abaixo o que os pesquisadores afirmam em relação aos $\mathrm{PCNs:}$

De qualquer forma, o importante mesmo seria definir os temas transversais por meio de uma consulta popular. Eles até poderiam passar por um "tratamento" feito por especialistas, porém precisariam justificar-se no coletivo. Tal processamento é provavelmente mais importante para os temas transversais do que para as disciplinas clássicas resultantes de uma tradição e de démarches científicas.

As denominadas "Áreas de Seguimento" contemplam: Educação Infantil (720 professores), Ensino Fundamental I (800 professores), Ensino Fundamental II (840 professores), Ensino de Artes (90 professores), Educação de Jovens e Adultos
(Seguimentos $1 .^{\circ}$ e $2 .^{\circ}-810$ professores), e outros segmentos escolares (pedagogos, psicólogos e assistentes sociais - 320 técnicos), totalizando 3.580 servidores, conforme dados do certame em análise.

No tocante à estrutura e à metodologia de trabalho de formação continuada, os critérios estabelecidos demandam que cada projeto:

(...) deverá estar embasado em uma proposta metodológica centrada na ação/ reflexão/ação, tendo como suporte teórico a concepção de que o conhecimento é construido pelo aluno, em situações de interação. A metodologia da formação deve ter como ponto de partida o contexto sócio-histórico, (sic) bem como a heterogeneidade de conhecimentos dos profissionais da educação e de alunos da rede municipal de ensino. A dinâmica de trabalho supõe a problematização, a busca coletiva de soluções, a interdisciplinaridade, tendo a teoria como fonte de informação para compreender, articular e atualizar a prática pedagógica das escolas e CREIS. Isto requer um modelo de trabalho pautado, prioritariamente (sic) no processo de desenvolvimento integral da criança, com ênfase na alfabetização e letramento, no respeito aos saberes do grupo e na vivência de metodologias de resolução de problemas, articulando conhecimentos didáticos com pressupostos teóricos das várias áreas do conhecimento, tais como: Linguística, Psicologia, Pedagogia, Saúde. (Processo Licitatório n. ${ }^{\circ} 007663 / 2009$ ).

O caráter de prescrição define, claramente, o caráter de intenção da Sedec. Desse ponto de vista, levantamos aqui algumas reflexões sobre os sentidos postos na estrutura e na metodologia de cada proposição de formação continuada direcionada à concorrência pública. O documento apresenta maneiras especíicas de ressignificar o trabalho docente, com efeitos nos modos de saber-fazer e nos modos de como deverá ser trabalhado o currículo por cada seguimento característico. Com base em critérios bastante precisos, estaria o professor inscrito em uma certa "tomada de consciência" sobre si mesmo e sobre sua prática pedagógica? Ainda de maneira precisa, o documento, além disso, estabelece parâmetros teóricos e práticos para o ensino e a aprendizagem de crianças, jovens e adultos: a abordagem interacionista e o principio sócio- 
histórico. O conceito de criança ancora-se nos preceitos, como um modo de articulação entre as linguagens, da psicologia, da linguística, da pedagogia, da saúde, da psicologia cognitiva, da enfermagem e da psicolinguística. Sobre o conceito de individuo, há uma ênfase no sujeito-reflexivo. Nesse sentido, as demandas apresentadas para a formação continuada traduzem uma formação discursiva que, na "ritualização" das palavras e no caráter normalizador, buscam inscrever o professor, tendo em vista que "Todo sistema de educação é uma maneira política de manter ou de modificar a apropriação dos discursos, com os saberes e os poderes que eles trazem consigo" (Foucault, 2003, p. 44).

\section{Perfil do professor formador}

Quando a SEDEC, a partir de suas proposições, pensa e operacionaliza ações de formação continuada e atendendo à legislação específica como a Lei n. 8.752 de 2016, que trata da Política Nacional de Formação, ela regula e atualiza, no interior da escola, um modo de produzir "visibilidades e enunciabilidades" de ser professor, em que são produzidos efeitos pela positividade das relações de saber-poder. Carvalho (2015, p. 468) sublinha que "Isso ocorre porque a conduta docente é um efeito discursivo, uma vez que o sujeito professor ocupa posições, derivadas de combinações, composições e adaptações de discursos e práticas".

Na proposta de formação, portanto, o professor formador representa o suporte acadêmico e científico de uma pedagogia institucionalizada, na medida em que o texto vai instituindo critérios sobre o que deve ou não ser produzido em sala de aula.

Os professores formadores deverão atuar na formação continuada, envolvendo atividades de ensino, de planejamento e de monitoramento de projetos didáticos, em conjunto com os professores, monitores e berçaristas que estão em processo de formação. (Processo Licitatório, n. ${ }^{\circ} 007663 / 2009$ ).

A equipe de formadores deverá ser interdisciplinar e composta por profissionais com as seguintes formações acadêmicas: Pedagogia ou áreas afins, com Pós-Graduação em Educação, com área de concentração em
Educação Infantil e/ou Psicopedagogia: Psicologia com Pós-Graduação em Psicologia Educacional, com área de concentração em Educação Infantil e/ou Psicopedagogia; Linguística e áreas afins, com Pós-Graduação na área de Aquisição da Linguagem e/ ou Psicolinguistica, profissional com graduação em Enfermagem. (Área de Seguimento - Educação Infantil, Processo Licitatório, n. ${ }^{\circ}$ 007663/2009).

O papel do formador deve ser de um parceiro experiente, capaz de favorecer a reflexão do professor, ajudando-o a identificar problemas e a planejar estratégias de intervenção, de modo crítico, dinâmico e interdisciplinar, levando-o a reconhecer os pressupostos teórico-metodológicos que os determinam bem como a sua responsabilidade, perante às decisões que afetam a sua prática profissional. (Área de Seguimento - Educação Fundamental I, Processo Licitatório, n. ${ }^{\circ} 007663 / 2009$.

Tais proposições buscam não apenas definir, mas estabelecer uma hierarquia na estruturação dos enunciados. Por essa perspectiva, há um certo ordenamento do ponto de vista do "olhar para si", e de se perceber nessa discursividade. Na ação pedagógica do professor formador, haveria uma espécie de vigilância constante que o docente exerce sobre si mesmo e os outros e que deve ser reativada. Desse modo, é preciso dizer, enunciar, aperfeiçoar, alterar etc., para se ter uma certa economia política dos discursos que se ocupam da produção de subjetividades.

Tal intelectual atua como mentor, guiando a conduta de todos (e de cada um). promovendo as carências de seu rebanho (através de sua "visão de mundo" e criticidade), como um conselheiro e pastor que estimula a participação e zela pelo cuidado e pela educação dos seus. (Carvalho, 2015, p. 474).

Por essa ordem de compreensão, aquilo que o professor formador "deve fazer" e "não fazer" referese à noção do discurso como prática. Por "prática":

(...) não se entende a atividade de um sujeito, e sim a existência objetiva e material de certas regras às quais o sujeito tem que obedecer quando participa do discurso. Os efeitos dessa disciplina do sujeito são analisados no exame das posições dos sujeitos. (Lecourt, 2008, p. 51). 
Os saberes da formação continuada passam, didaticamente, a inscrever o professor formador em uma prática discursiva especifica e contingencial. E quais são as posições que ele ocupa nessa ordem?

Nessa direção, e na formação permanente do professor no interior desses espaços visiveis de sujeição, para Larrosa (1994, pp. 54-55):

(...) os sujeitos não são posicionados como objetos silenciosos, mas como sujeitos falantes; não como objetos examinados, mas como sujeitos confessantes; não em relação a uma verdade sobre si mesmos que lhes é imposta de fora, mas em relação a uma verdade sobre si mesmos que eles mesmos devem contribuir ativamente para produzir.

Ao inscrever o sujeito - o "formador e em processo de formação" - nessa ordem do discurso, o uso do sintagma "deve" e suas variações são, e aqui estamos tomando por base as análises de Carvalho (2015), o fundamento, a norma contida no atributo, em específico, prescritivo da formação continuada. O que deve ser dito ou não no campo educacional "(...) permite aos seus enunciados se inscreverem em determinado horizonte teórico ao definirem o que pertence a esse campo e os limites entre proposições verdadeiras ou falsas. (...)" (p. 474).

\section{Considerações finais}

A tentativa de problematizar a formação continuada de professores, sobretudo quando as preocupações para pensar e tematizar a formação como um campo teórico e prático se apresentam no contemporâneo, ancora-se na perspectiva de compreender o Processo Licitatório n. ${ }^{\circ}$ 007663/2009 como um dispositivo que, ao procurar responder a uma certa urgência histórica sobre a produção do sujeito producente, seu discurso, previamente definido, customiza-se às legislações especificas da formação continuada.

Os enunciados que atribuem materialidade à formação continuada de professores constituem um campo associativo que indica o exercício de uma prática discursiva e não discursiva em que a noção do professor em formação é reinterpretada, ressignificada e posta em circulação em uma certa "ordem do discurso". Neste sentido, é pertinente afirmar que há, no documento em análise, uma distribuição que orienta o saber-fazer pedagógico e que essa mesma distribuição obedece a uma certa lógica que organiza e faz articular modos de pensar, de dizer e de agir, ou seja, enunciados que sustentam que tipo de conduta deve ser adotada pelo professor no planejamento, nos processos avaliativos, na relação com o aluno em sala de aula etc. Tornar o sujeito producente é ativar, em um feixe de relações de saber-poder, uma certa economia politica do discurso que, em um campo associativo, procura atualizar e responder a uma certa urgência histórica.

O método da arqueologia foucaultiana nos permite situar o enunciado sempre como um acontecimento pela sua materialidade. A prática discursiva que inscreve e marca um modo de operar e otimizar o saber-fazer do professor, como pudemos observar na proposta do Processo Licitatório, vai falar do professor da formação continuada. Não existe, portanto, a "realidade" do professor em formação. Essa realidade se situa na irrupção de práticas que produzem determinados objetos que "trazem em si" e que obedecem a um certo "regime de verdade". Sendo assim, é possivel afirmar que o objeto "(...) é inteiramente constituido por relações discursivas. (...)" (Rouanet, 2008, p. 112). O professor, como sujeito do enunciado, enuncia uma verdade em uma determinada contingência histórica.

Na proposta do método da arqueologia, e como experiência para discutir o discurso da formação continuada, não há lugar para a "opacidade" da análise sobre a produção do sujeito. O Processo Licitatório não é um documento neutro, imparcial. Ele estabelece relações de saber-poder em filigranas de forças que, ao mesmo tempo em que faz funcionar a engrenagem do chão da escola, instaura, também, uma certa ordem moral e simbólica do sujeito, do modo como ele tem que "olhar para si", e se reconhecer como o "sujeito da educação".

Nesse sentido, e nos diferentes modos que fabricam outras significações, outras territorialidades do saber-fazer pedagógico do professor, a presente análise pretendeu deslocar 
o modo como se tem refletido sobre a formação continuada, buscando pensá-la, juntamente com arqueologia foucaultiana do discurso e do enunciado, também como território de invenção, de criação, frente a um certo "pedagogismo" de expressão mercantil, que não para de instituir verdades sobre a prática docente.

Por fim, compreendemos o sujeito como um feixe de múltiplas forças que inventa e produz outras subjetivações no embate das práticas pedagógicas que regulam e normatizam atitudes e comportamentos, em específico, nos espaços da educação escolar, afeitos à governamentalidade de racionalidade neoliberal.

\section{Referências}

Bonfim, A., Anjos, M., Floriano, M., Figueiredo, C., Santos, D., \& Silva, C. (2013). Parâmetros Curriculares Nacionais: uma revisita aos temas transversais meio ambiente e saúde. Trabalho, Educação e Saúde, 11(1), 27-52. https://doi.org/10.1590/S198177462013000100003

Brzezinski, I. (2014). Sujeitos sociais coletivos e a política de formação inicial e continuada emergencial de professores: contradições vs conciliações. Educação \& Sociedade, 35(129), 1241-1259. https:// doi.org/10.1590/ES0101-73302014146309.

Carvalho, R. (2015). Análise do discurso das diretrizes curriculares nacionais de educação infantil: currículo como campo de disputas. Educação, 38(3), 466-476. https://doi.org/10.15448/1981-2582.2015.3.15782.

Cruz Junior, A. F. da, Della Fonte, S. S., \& Loureiro, R. (2014). Formação continuada de professores: quando a experiência e os saberes docentes se limitam à vivência. Pro-Posições, 25(2), 197-215. https://doi. org/10.1590/S0103-73072014000200011.

Decreto-Lei n. 8.752, de 9 de maio de 2016. (2016). Dispõe sobre a Política Nacional de Formação dos Profissionais da Educação Básica. Portal da legislação. Brasilia, DF.

Fernandes, F. (1986). A formação política e o trabalho do professor. In D. Catani, H. Miranda, L. Menezes \& R. Fischmann (Eds.). Universidade, escola e formação de professores (pp. 13-37). São Paulo: Brasiliense.

Foucault, M. (2003). A ordem do discurso. São Paulo: Loyola.

Foucault, M. (2008). A Arqueologia do saber. Rio de Janeiro: Forense Universitária.

Freitas, H. (2007). A (nova) politica de formação de professores: a prioridade postergada. Educação \& Sociedade, 28(100), 1203-1230. https://doi. org/10.1590/S0101-73302007000300026.
Gatti, B. (2008). Análise das políticas públicas para formação continuada no Brasil, na última década. Revista Brasileira de Educação, 13(37), 57-70. https:// doi.org/10.1590/S1413-24782008000100006.

Geglio, P. (2015). Políticas públicas de formação continuada para professores: um estudo de cursos realizados a partir de propostas licitatórias. Ensaio: Avaliação e Politicas Públicas em Educação, 23(86), 231-257. https://doi.org/10.1590/S010440362015000100009 .

Goldenberg, M. (1997). A arte de pesquisar. Como fazer pesquisa qualitativa em Ciências Sociais. Rio de Janeiro: Record.

Larrosa, J. (1994). Tecnologias do Eu e Educação. In T. T. Silva (Ed.), O sujeito da educação: Estudos foucaultianos. Petrópolis, RJ: Vozes.

Lecourt, D. (2008). A Arqueologia e o Saber. In M. Foucault, S. Rouanet, J. Merquior, D. Lecourt \& C. Escobar (Eds.), O homem e o discurso. (A Arqueologia de Michel Foucault) (pp. 43-66). Rio de Janeiro: Tempo Brasileiro.

Lei n. 9.394, de 20 de dezembro de 1996. (1996). Estabelece as diretrizes e bases da educação nacional. Diário Oficial da União. Brasilia, DF.

Lourau, R. (1993). Análise Institucional e Práticas de Pesquisa. Rio de Janeiro: UERJ.

Rouanet, S. (2008). A Gramática do Homicídio. In M. Foucault, S. Rouanet, J. Merquior, D. Lecourt \& C. Escobar (Eds.), O homem e o discurso. (A Arqueologia de Michel Foucault) (pp. 91-139). Rio de Janeiro: Tempo Brasileiro.

Veiga, A., Neto. (2007). Foucault \& a Educação (2. ed.) Belo Horizonte: Autêntica.

Prefeitura Municipal de João Pessoa. (2009). Processo Licitatório n. 007663. João Pessoa: Secretaria de Educação.

\section{Eduardo Antonio De Pontes Costa}

Doutor em Educação pela Universidade Federal Fluminense (UFF, Niterói, RJ, Brasil), professor associado da Universidade Federal da Paraíba em João Pessoa, PB, Brasil.

\section{Décio Pereira de Brito}

Pedagogo pela Universidade Federal da Paraiba (UFPB, João Pessoa, PB, Brasil).

\section{Endereço para correspondência}

Eduardo Antonio de Pontes Costa

Universidade Federal da Paraiba

Centro de Educação, Sala 11

Cidade Universitária, 58051-900

João Pessoa, PB, Brasil 